\title{
Generalization of the Graph of Fuzzy Topographic Topological Mapping
}

\author{
Mohamed Sayed ${ }^{\mathrm{a}, \mathrm{c}}$, Tahir Ahmad ${ }^{\mathrm{a}, \mathrm{b}^{*}}$ \\ ${ }^{a}$ Department of Mathematical Science, Faculty of Science, Universiti Teknologi Malaysia, 81310 UTM Johor Bahru, Johor, Malaysia. \\ ${ }^{b}$ Ibnu Sina Institute, Universiti Teknologi Malaysia, 81310 UTM Johor Bahru, Johor, Malaysia. \\ ${ }^{c}$ Department of Mathematical Science, Faculty of Science, International University of Africa, Sudan \\ *Corresponding Author: tahir@ibnusina.utm.my (Tahir Ahmad)
}

\section{Article history :}

Received 19 November 2015

Accepted 08 December 2015

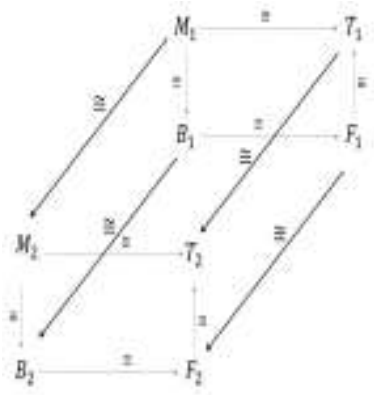

\begin{abstract}
In 1999, Tahir et. al. developed the Fuzzy Topographic Topological Mapping to determine the location of epileptic foci in epilepsy disorder patients. The model which consists of topological and fuzzy structure is composed into three mathematical algorithms. There are two FTTMs up to now, namely FTTM version 1 and FTTM version 2. FTTM version 1 is homeomorphic to FTTM version 2 . The homeomorphism of FTTM can be presented using graphs. In this paper, we generalized the graph of FTTM. In other words, we will prove that, if there exist k versions of FTTM, the new elements will produce a graph of degree $8 \mathrm{k}^{3}+8 \mathrm{k}-24$.

Keywords: FTTM, Sequence of FTTM, Elements Order, Graph of FTTM

(C) 2015 Penerbit UTM Press. All rights reserved http://dx.doi.org/10.11113/mjfas.v11n4.395
\end{abstract}

\subsection{INTRODUCTION}

\section{3}

Epilepsy affects about $1 \%$ of the world population $[1,2]$. It is one of the most prevalent neurological disorders $[3,4]$, and a group of related defects characterized by a repeated seizures $[5,6]$. Epilepsy happens as a result of abnormal electrical activity in the brain $[6,1]$. Brain cells are connected by sending electrical signals in an organized pattern. In epilepsy these electrical signals become abnormal [1, 6], therefore they produce seizures. These signals can be within a certain part or be spread in the brain. Seizures are classified as focal [7] (when seizures appear just in one area of the brain) [8, 9], or generalized [7] (Seizures that appear in all areas of the brain) $[8,10]$. Epilepsies are mainly caused by genetic factors $[11,8]$, while the others are gained / etiological epilepsies [11, 1]. There are many factors involved in the appearance of epileptic seizures, including ischemic injury, tumors, and trauma [12]. Epilepsy can be a complication of many immunological and inflammatory diseases affecting the central nervous system.

In 1999, Tahir et. al [13], developed the Fuzzy Topological Mapping (FTTM) technique, in which involved the introduction of the MEG / EEG signals to a fuzzified space, with the aim of identifying the location of the epileptic foci, i.e. the point at which the seizure emanates.

FTTM version 1 (Fig.1) was developed to present a 3-D view of unbounded signal current source $[14,15]$

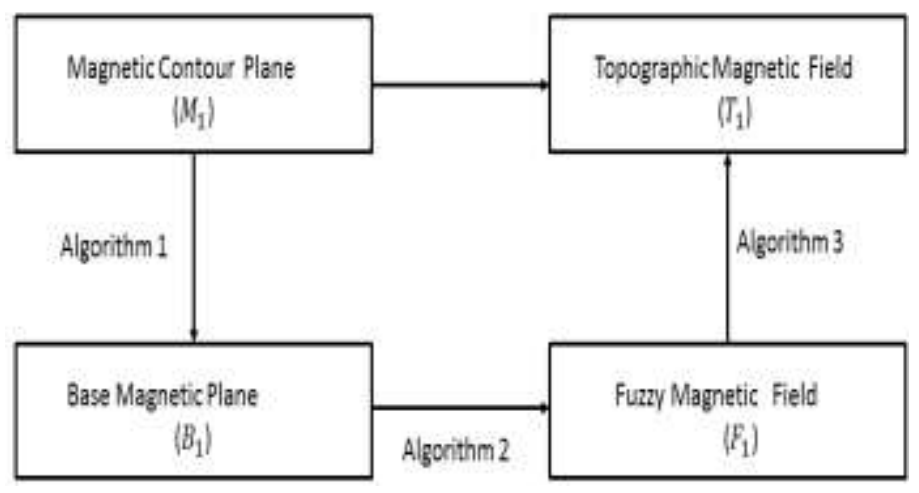

Fig. 1 FTTM 1

Besides that, FTTM version 2 (Fig.2) can process image data of magnetic field. 


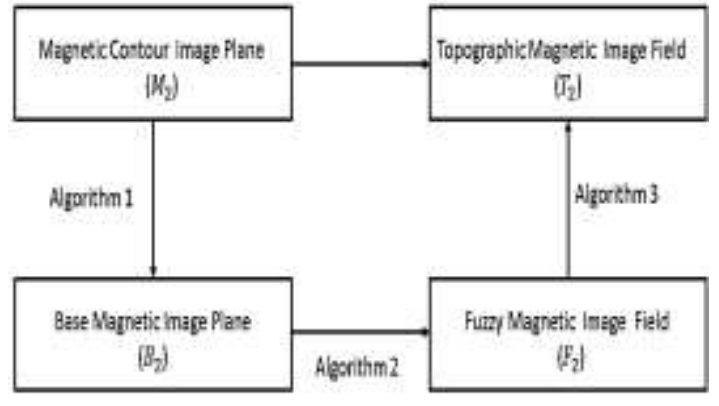

Fig. 2 FTTM2

FTTM version 1 as well as FTTM version 2 is specially designed to have equivalent topological structures between its components [16]. In other words, there are homeomorphisms between each element of FTTM version 1 and FTTM version 2 (Figure 3) [16, 17].

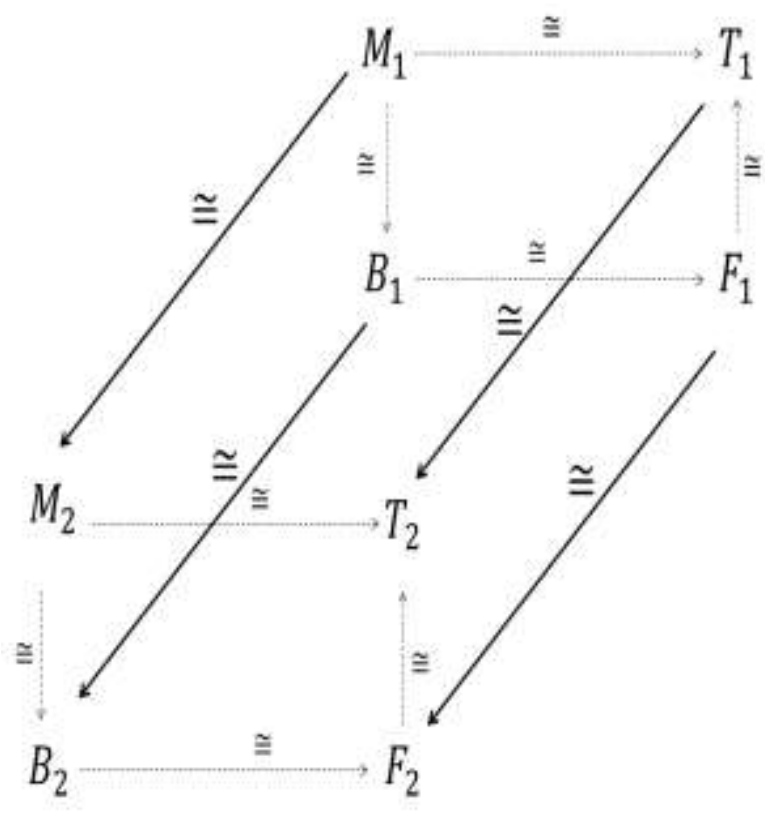

Figure.3 Homeomorphism between FTTM 1 and FTTM 2

\section{MATERIALS AND METHOD}

In this paper our main focus will be on the graph of the new elements of order two, three and four. Firstly, we will present that if there exist $k$ elements of FTTM, the new elements of order two will produce a graph of degree $24 \mathrm{k}^{2}-16 \mathrm{k}-8$. In addition, we will prove that, the new elements of order three will produce a graph of degree $8 \mathrm{k}^{3}-24 \mathrm{k}^{2}+24 \mathrm{k}-8$, and the new elements of order four will produce a graph of degree $8 \mathrm{k}-8$. Finally, the degree of the graph of the new elements of FTTM will be computed by summing up the degree of the graphs of the new elements of order two, three and four.

\subsection{1 Graph of Finite Sequence of Fuzzy Topographic Topological Mapping of Order 2}

\section{Definition 1: [18]}

Let FTTM $_{i}=\left(M_{i}, B_{i}, F_{i}, T_{i}\right)$ be FTTM version $i$ such that $M_{i}, B_{i}, F_{i}$ and $T_{i}$ are topological spaces with $M_{i} \cong$ $B_{i} \cong F_{i} \cong T_{i}$. The sequence of $k$ FTTM is

$$
\text { FTTM }^{k}=\left\{\text { FTTM }_{1}, \text { FTTM }_{2}, \text { FTTM }_{3}, \cdots, \text { FTTM }_{k}\right\}
$$

Such that

$$
M_{i} \cong M_{i+1}, B_{i} \cong B_{i+1}, F_{i} \cong F_{i+1}, T_{i} \cong T_{i+1}
$$

Definition 2: [19]

Let FTTM $^{k}=\left\{\right.$ FTTM $_{1}$, FTTM $_{2}$, FTTM $_{3}, \cdots$, FTTM $\left._{k}\right\}$

be a sequence of $k$ FTTM. then

1. The cube that produced from a combination of $i$ versions of the sequence of FTTM is said to be a cube of order $i$ and $i=2,3,4$.

2. $C_{i, j}$ FTTM $^{k}$ represents the cube of order two that can be produced from the combination of FTTM $_{i}$ and FTTM $_{j}$ in FTTM $^{k}$, where $1 \leq i \leq j \leq k$

3. $\mid C_{i, j}$ FTTM $\left.^{k}\right|_{1 \leq i \leq j \leq k}$ represents the number of cubes of order two that can be produced from the combination of FTTM $_{i}$ and FTTM $_{j}$ in $F T T M^{k}$, such that $1 \leq i \leq j \leq k$

Definition 3: [20]

2. The new element is said to be an element of order $i$ if its components appear in exactly $i$ versions of FTTM $^{k}$.

3. $\alpha_{a}$ FTTM $^{k}$ represents the set of all elements of order $a$ that can be generated by FTTM $^{k}$.

Theorem 1: [19]

$$
\left|\alpha_{a} \operatorname{FTTM}^{k}\right|=7\left(k^{2}-k\right)
$$

Theorem 2: [19]

The new elements of order two will produce a graph of degree $\left(24 k^{2}-16 k-8\right)$

\subsection{Graph of Finite Sequence of Fuzzy Topographic Topological Mapping of Order 3}

3.3

\section{Definition 4:}

1. $C_{i, j, l} F T T M^{k}$ represents the cube of order three that can be produced from the combination of FTTM $_{i}$, 


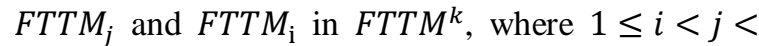
$l \leq k$

2. $\mid C_{i, j, l}$ FTTM $\left.^{k}\right|_{1 \leq i<j<l \leq k}$ represents the number of cubes of order three that can be presented from the combination of FTTM $_{i}$, FTTM $_{j}$ and FTTM $M_{l}$ in FTTM $^{k}$ such that $1 \leq i<j<l \leq k$

\section{Lemma 1:}

$$
\mid C_{i, j, l} \text { FTTM }\left.^{k}\right|_{1 \leq i<j<l \leq k}=\frac{k(k-1)(k-2)}{6}
$$

\section{Proof:}

The number of ways to choose three versions from a sequence of $k$ version is $\left(\begin{array}{l}k \\ 3\end{array}\right)$. Thus

$$
\begin{aligned}
\mid C_{i, j, l} \text { FTTM }\left.^{k}\right|_{1 \leq i<j<l \leq k} & =\left(\begin{array}{l}
k \\
3
\end{array}\right) \\
& =\frac{k !}{3 !(k-1) !} \\
& =\frac{k(k-1)(k-2)}{6}
\end{aligned}
$$

\section{Lemma 2:}

Any $C_{i, j, l}$ FTTM $^{k}$ will generate 36 new elements of order 3 .

\section{Proof:}

The new elements can be generated by simple construction as given below:

$$
\begin{aligned}
& \left(M_{i}, B_{i}, F_{j}, T_{l}\right),\left(M_{i}, B_{i}, F_{l}, T_{j}\right),\left(M_{j}, B_{j}, F_{i}, T_{l}\right), \\
& \left(M_{j}, B_{j}, F_{l}, T_{i}\right),\left(M_{l}, B_{l}, F_{i}, T_{j}\right),\left(M_{l}, B_{l}, F_{j}, T_{i}\right), \\
& \left(M_{i}, B_{j}, F_{j}, T_{l}\right),\left(M_{l}, B_{j}, F_{j}, T_{i}\right),\left(M_{j}, B_{i}, F_{i}, T_{l}\right), \\
& \left(M_{l}, B_{i}, F_{i}, T_{j}\right),\left(M_{i}, B_{l}, F_{l}, T_{j}\right),\left(M_{j}, B_{l}, F_{l}, T_{i}\right), \\
& \left(M_{i}, B_{j}, F_{l}, T_{i}\right),\left(M_{i}, B_{l}, F_{j}, T_{i}\right),\left(M_{j}, B_{i}, F_{l}, T_{j}\right), \\
& \left(M_{j}, B_{l}, F_{i}, T_{j}\right),\left(M_{l}, B_{i}, F_{j}, T_{l}\right),\left(M_{l}, B_{j}, F_{i}, T_{l}\right), \\
& \left(M_{j}, B_{l}, F_{i}, T_{i}\right),\left(M_{l}, B_{j}, F_{i}, T_{i}\right),\left(M_{i}, B_{l}, F_{j}, T_{j}\right), \\
& \left(M_{l}, B_{i}, F_{j}, T_{j}\right),\left(M_{i}, B_{j}, F_{l}, T_{l}\right),\left(M_{j}, B_{i}, F_{l}, T_{l}\right), \\
& \left(M_{i}, B_{j}, F_{i}, T_{l}\right),\left(M_{j}, B_{i}, F_{j}, T_{l}\right),\left(M_{i}, B_{l}, F_{i}, T_{j}\right), \\
& \left(M_{j}, B_{l}, F_{j}, T_{i}\right),\left(M_{i}, B_{j}, F_{l}, T_{j}\right),\left(M_{j}, B_{i}, F_{l}, T_{i}\right),
\end{aligned}
$$

$$
\begin{aligned}
& \left(M_{l}, B_{j}, F_{l}, T_{i}\right),\left(M_{i}, B_{l}, F_{i}, T_{j}\right),\left(M_{l}, B_{i}, F_{l}, T_{j}\right), \\
& \left(M_{i}, B_{j}, F_{i}, T_{l}\right),\left(M_{l}, B_{j}, F_{i}, T_{j}\right),\left(M_{i}, B_{l}, F_{j}, T_{l}\right) .
\end{aligned}
$$

All of the above elements are of order three.

\section{Theorem 3:}

$$
\left|\alpha_{3} \operatorname{FTTM}^{k}\right|=6 k^{3}-18^{2}+12 k
$$

\section{Proof:}

From Lemma 1 and Lemma 2

$$
\begin{aligned}
\mid \alpha_{3} \text { FTTM }^{k}|=36| C_{i, j, l} \text { FTTM }\left.^{k}\right|_{1 \leq i<j<l \leq k} \\
\quad=36 \times \frac{(k(k-1)(k-2))}{6} \\
=6\left(k^{2}-1\right)(k-2) \\
=6\left(k^{3}-3 k^{2}+2 k\right) \\
=6 k^{3}-18 k^{2}+12 k
\end{aligned}
$$

\section{Lemma 3:}

Any element of order three will produce a graph of degree 2 or 0 .

\section{Proof:}

From Lemma 2, we know that FTTM $_{i}$, FTTM $_{j}$ and FTTM $_{l}$ will generate 36 new elements of order three; 24 elements will produce a graph of degree 2 ; which are

$$
\begin{aligned}
& \left(M_{i}, B_{i}, F_{j}, T_{l}\right),\left(M_{i}, B_{i}, F_{l}, T_{j}\right),\left(M_{i}, B_{j}, F_{j}, T_{l}\right), \\
& \left(M_{i}, B_{j}, F_{l}, T_{i}\right),\left(M_{i}, B_{j}, F_{l}, T_{l}\right),\left(M_{i}, B_{l}, F_{j}, T_{i}\right), \\
& \left(M_{i}, B_{l}, F_{j}, T_{j}\right),\left(M_{i}, B_{l}, F_{l}, T_{j}\right),\left(M_{j}, B_{j}, F_{i}, T_{l}\right), \\
& \left(M_{j}, B_{j}, F_{l}, T_{i}\right),\left(M_{j}, B_{i}, F_{i}, T_{l}\right),\left(M_{j}, B_{i}, F_{l}, T_{j}\right), \\
& \left(M_{j}, B_{i}, F_{l}, T_{l}\right),\left(M_{j}, B_{l}, F_{i}, T_{j}\right),\left(M_{j}, B_{l}, F_{i}, T_{i}\right), \\
& \left(M_{j}, B_{l}, F_{l}, T_{i}\right),\left(M_{l}, B_{l}, F_{i}, T_{j}\right),\left(M_{l}, B_{l}, F_{j}, T_{i}\right), \\
& \left(M_{l}, B_{i}, F_{i}, T_{j}\right),\left(M_{l}, B_{i}, F_{j}, T_{l}\right),\left(M_{l}, B_{i}, F_{j}, T_{j}\right), \\
& \left(M_{l}, B_{j}, F_{i}, T_{l}\right),\left(M_{l}, B_{j}, F_{i}, T_{i}\right),\left(M_{l}, B_{j}, F_{j}, T_{i}\right)
\end{aligned}
$$

while 12 elements will produce a graph of degree zero, because all its vertices are isolated; which are

$$
\begin{aligned}
& \left(M_{i}, B_{j}, F_{i}, T_{l}\right),\left(M_{i}, B_{j}, F_{l}, T_{j}\right),\left(M_{i}, B_{l}, F_{i}, T_{j}\right), \\
& \left(M_{i}, B_{l}, F_{j}, T_{l}\right),\left(M_{j}, B_{i}, F_{j}, T_{l}\right),\left(M_{j}, B_{i}, F_{l}, T_{i}\right),
\end{aligned}
$$




$$
\begin{aligned}
& \left(M_{j}, B_{l}, F_{j}, T_{i}\right),\left(M_{j}, B_{l}, F_{i}, T_{l}\right),\left(M_{l}, B_{i}, F_{l}, T_{j}\right), \\
& \left(M_{l}, B_{i}, F_{j}, T_{i}\right),\left(M_{l}, B_{j}, F_{l}, T_{i}\right),\left(M_{l}, B_{j}, F_{i}, T_{j}\right)
\end{aligned}
$$

\section{Theorem 4:}

The new elements of order three will produce a graph of degree $8 \mathrm{k}^{2}-24 \mathrm{k}+16$.

\section{Proof:}

From Lemma 1, Lemma 2 and Lemma 3 we can obtain the degree of $\alpha_{3} F T T M^{k}$ as follows.

$$
\begin{aligned}
& \operatorname{deg}\left(\alpha_{3} F_{T T M}{ }^{k}\right) \\
& \qquad \begin{aligned}
& \frac{k(k-1)(k-2)}{6} \times(24) \times(2)+H \\
&= 8\left(k^{2}-k\right)(k-2)+H \\
&= 8\left(k^{3}-3 k^{2}+2 k\right)+H \\
&= 8\left(k^{3}-24 k^{2}+16 k\right)+H
\end{aligned}
\end{aligned}
$$

where $H$ is the number of edges that have to be added to the graph due to the fact that $F T T M_{i}$ and FTTM $_{i+1}$ are homeomorphic component wise, therefore

$$
\begin{aligned}
H & =2(4)+8(k-2) \\
& =8+8 k-16 \\
& =8 k-8
\end{aligned}
$$

Substitute (2) in (1) we can have

$$
\begin{aligned}
\operatorname{deg}\left(\alpha_{3} \text { FTTM }^{k}\right) & =8 k^{3}-24 k^{2}+16 k+8 k-8 \\
& =8 k^{3}-24 k^{2}+24 k-8
\end{aligned}
$$

\subsection{Graph of Finite Sequence of Fuzzy Topographic Topological Mapping of Order 4}

\section{4}

\section{Definition 5:}

1. $C_{i, j, l, m} F T T M^{k}$ represents the cube of order four that can be produced from the combination of FTTM $_{i}$, FTTM $_{j}$, FTTM $_{l}$ and FTTM $m$ in FTTM $^{k}$, where $1 \leq i<j<l<m \leq k$

2. $\left|C_{i, j, l, m} F_{T T M}\right|_{1 \leq i<j<l<m \leq k} \quad$ represents the number of cubes of order four that can be presented from the combination of FTTM $_{i}$, FTTM $_{j}$, FTTM $_{l}$

$$
\underset{k}{\text { and } \text { FTTM }_{m} \text { in } \text { FTTM }^{k} \text {, such that } 1 \leq i<j<l<m \leq}
$$

\section{Lemma 4:}

$$
\begin{aligned}
\left.\left|C_{i, j, l, m} F_{T T M}\right|^{1}\right|_{1<i<j<l<m \leq k} \\
\\
=\frac{k(k-1)(k-2)(k-3)}{24}
\end{aligned}
$$

Proof:

The number of ways to choose four versions from a sequence of $k$ version is $\left(\begin{array}{l}k \\ 4\end{array}\right)$. Thus

$$
\begin{aligned}
\mid C_{i, j, l, m} \text { FTTM }\left.^{k}\right|_{1 \leq i<j<l<m \leq k}=\left(\begin{array}{l}
k \\
4
\end{array}\right) \\
=\frac{k !}{4 !(k-4) !} \\
=\frac{k(k-1)(k-2)(k-3)}{24}
\end{aligned}
$$

\section{Lemma 5:}

Any $C_{i, j, l, m}$ FTTM $^{k}$ will generate 24 new elements of order 4.

Proof:

The new elements can be generated by simple construction, as given below.

$$
\begin{aligned}
& \left(M_{i}, B_{j}, F_{l}, T_{m}\right),\left(M_{i}, B_{j}, F_{m}, T_{l}\right),\left(M_{i}, B_{l}, F_{j}, T_{m}\right), \\
& \left(M_{i}, B_{l}, F_{m}, T_{j}\right),\left(M_{i}, B_{m}, F_{j}, T_{l}\right),\left(M_{i}, B_{m}, F_{l}, T_{j}\right), \\
& \left(M_{j}, B_{i}, F_{l}, T_{m}\right),\left(M_{j}, B_{i}, F_{l}, T_{m}\right),\left(M_{j}, B_{l}, F_{i}, T_{m}\right), \\
& \left(M_{j}, B_{l}, F_{m}, T_{i}\right),\left(M_{j}, B_{m}, F_{i}, T_{l}\right),\left(M_{j}, B_{m}, F_{l}, T_{i}\right), \\
& \left(M_{l}, B_{j}, F_{i}, T_{m}\right),\left(M_{l}, B_{j}, F_{m}, T_{i}\right),\left(M_{l}, B_{i}, F_{j}, T_{m}\right), \\
& \left(M_{l}, B_{i}, F_{m}, T_{j}\right),\left(M_{l}, B_{m}, F_{j}, T_{i}\right),\left(M_{l}, B_{m}, F_{i}, T_{j}\right), \\
& \left(M_{m}, B_{i}, F_{l}, T_{j}\right),\left(M_{m}, B_{j}, F_{i}, T_{l}\right),\left(M_{m}, B_{l}, F_{j}, T_{i}\right), \\
& \left(M_{m}, B_{l}, F_{i}, T_{j}\right),\left(M_{m}, B_{i}, F_{j}, T_{l}\right),\left(M_{m}, B_{i}, F_{l}, T_{j}\right),
\end{aligned}
$$

All of the above elements are of order four.

\section{Theorem 5:}

$\mid\left(\alpha_{4}\right.$ FTTM $\left.^{k}\right) \mid=k(k-1)(k-2)(k-3)$ 


\section{Proof:}

From Lemma 4 and Lemma 5 we can find that

$$
\begin{gathered}
\mid\left(\alpha_{4} \text { FTTM }^{k}\right)|=24| C_{i, j, l, m} \text { FTTM }\left.^{k}\right|_{1 \leq i<j<l<m \leq k} \\
=24 \frac{k(k-1)(k-2)(k-3)}{24} \\
=k(k-1)(k-2)(k-3)
\end{gathered}
$$

\section{Lemma 6:}

Any element of order four will produce a graph of degree zero.

Proof:

From Lemma 5 we know that FTTM $_{i}$, FTTM $_{j}$, FTTM $_{l}$ and FTTM $_{m}$ will generate 24 new elements of order four; but all of them will produce a graph of degree zero, because all its vertices are isolated as given below.

$$
\begin{aligned}
& \left(M_{i}, B_{j}, F_{l}, T_{m}\right),\left(M_{i}, B_{j}, F_{m}, T_{l}\right),\left(M_{i}, B_{l}, F_{j}, T_{m}\right), \\
& \left(M_{i}, B_{l}, F_{m}, T_{j}\right),\left(M_{i}, B_{m}, F_{j}, T_{l}\right),\left(M_{i}, B_{m}, F_{l}, T_{j}\right), \\
& \left(M_{j}, B_{i}, F_{l}, T_{m}\right),\left(M_{j}, B_{i}, F_{l}, T_{m}\right),\left(M_{j}, B_{l}, F_{i}, T_{m}\right), \\
& \left(M_{j}, B_{l}, F_{m}, T_{i}\right),\left(M_{j}, B_{m}, F_{i}, T_{l}\right),\left(M_{j}, B_{m}, F_{l}, T_{i}\right), \\
& \left(M_{l}, B_{j}, F_{i}, T_{m}\right),\left(M_{l}, B_{j}, F_{m}, T_{i}\right),\left(M_{l}, B_{i}, F_{j}, T_{m}\right), \\
& \left(M_{l}, B_{i}, F_{m}, T_{j}\right),\left(M_{l}, B_{m}, F_{j}, T_{i}\right),\left(M_{l}, B_{m}, F_{i}, T_{j}\right), \\
& \left(M_{m}, B_{i}, F_{l}, T_{j}\right),\left(M_{m}, B_{j}, F_{i}, T_{l}\right),\left(M_{m}, B_{l}, F_{j}, T_{i}\right), \\
& \left(M_{m}, B_{l}, F_{i}, T_{j}\right),\left(M_{m}, B_{i}, F_{j}, T_{l}\right),\left(M_{m}, B_{i}, F_{l}, T_{j}\right)
\end{aligned}
$$

\section{Theorem 6:}

The new elements of order four will produce a graph of degree $8 \mathrm{k}-8$.

\section{Proof:}

From Lemma 4, Lemma 5 and Lemma 6 we can obtain the degree of $\left(\alpha_{4}\right.$ FTTM $\left.^{\mathrm{k}}\right)$ as follows.

$$
\begin{aligned}
\operatorname{deg}\left(\alpha_{4} F T T M^{k}\right) & =(k(k-1)(k-2)(k-3)) \times(24) \\
& \times(0)+H \\
& =H
\end{aligned}
$$

where $H=8 k-8$ (from Equation 2). Thus

$$
\left(\alpha_{4} \text { FTTM }^{k}\right)=8 k-8
$$

\subsection{Graph of Finite Sequence of Fuzzy Topographic Topological Mapping}

3.5

Finally, we can compute the degree of the graph of finite sequences of FTTM.

\section{Theorem 7:}

Let $\operatorname{deg}\left(F T T M^{k}\right)$ to represent the degree of the graph of finite sequences of FTTM. Then

$$
\operatorname{deg}\left(F_{T T M}^{k}\right)=8 k^{3}+16 k-24
$$

\section{Proof:}

From Theorem 2, Theorem 4, and Theorem 5 we can find that

$$
\begin{aligned}
& \operatorname{deg}\left(\text { FTTM }^{k}\right)=\left(24 k^{2}-16 k-8\right) \\
&+\left(8 k^{3}-24 k^{2}+24 k-8\right)+(8 k-8) \\
&=8 k^{3}+16 k-24
\end{aligned}
$$

\section{RESULTS AND DISCUSSION}

In this paper, it is presented that if there exist $k$ elements of FTTM, the new elements of order two will produce a graph of degree $\left(24 k^{2}-16 k-8\right)$. In addition to the above result, it is also shown that the new elements of order three will produce a graph of degree $\left(8 \mathrm{k}^{2}-24 \mathrm{k}+\right.$ 16). while the new elements of order four will produce a graph of degree $(8 k-8)$. Finally, the degree of the graph of the new elements of FTTM was computed by summing up the degree of the graphs of the new elements of order two, three and four.

\section{CONCLUSION}

The result of this paper generalized the graph of FTTM . Furthermore, categorization of the new elements was done by finding the degree of the graph where it was found that some of the new elements are producing graphs of degree zero signifying that they have isolated components.

\section{ACKNOWLEDGEMENTS}

This work was supported by University Grant No 041194 . 


\section{REFERENCES}

[1] Chao, D., Shen, X. and Xia, Y., (2013). From Acupuncture to Interaction between-Opioid Receptors and $\mathrm{Na}(+)$ Channels: A Potential Pathway to Inhibit Epileptic Hyperexcitability. Evidencebased complementary and alternative medicine: eCAM, 2012: 216016-216016.

[2] Mirza, N., Vasieva, O., Marson, A. G. and Pirmohamed, M. (2011). Exploring the genomic basis of pharmacoresistance in epilepsy: an integrative analysis of large-scale gene expression profiling studies on brain tissue from epilepsy surgery. Human molecular genetics, 20(22): 4381-4394.

[3] Giorgi, F. S., Pizzanelli, C., Pelliccia, V., Di Coscio, E., Maestri, M., Guida, M., Iacopini, E., Iudice, A. and Bonanni, E., (2013). A Clinical-EEG Study of Sleepiness and Psychological Symptoms in Pharmacoresistant Epilepsy Patients Treated with Lacosamide. Epilepsy research and treatment.

[4] Singh, P., Kaur, R., Saggar, K., Singh, G. and Kaur, A., (2013). Qualitative and Quantitative Hippocampal MRI Assessments in Intractable Epilepsy. BioMed research international.

[5] Hosseini, S., Akbarzadeh-T, M. and Naghibi-Sistani, M., (2013). Qualitative and Quantitative Evaluation of EEG Signals in Epileptic Seizure Recognition. International Journal of Intelligent Systems and Applications (IJISA).

[6] Fisher, R. S., Boas, W. v. E., Blume, W., Elger, C., Genton, P., Lee, P. and Engel, J., (2005) Epileptic seizures and epilepsy: definitions proposed by the International League Against Epilepsy (ILAE) and the International Bureau for Epilepsy (IBE). Epilepsia. 46(4): 470472.

[7] Schindler, K., Gast, H., Goodfellow, M. and Rummel, C., (2012). On seeing the trees and the forest: Single-signal and multisignal analysis of periictal intracranial EEG. Epilepsia. 53(9): 1658-1668.

[8] Lerche, H., Shah, M., Beck, H., Noebels, J., Johnston, D. and Vincent, A. , (2012). Ion channels in genetic and acquired forms of epilepsy. The Journal of physiology. 591.4.

[9] Altenmüller, D.-M., Hebel, J. M., Rassner, M. P., Volz, S., Freiman, T. M., Feuerstein, T. J. and Zentner, J., (2013). Locally Applied Valproate Enhances Survival in Rats after Neocortical Treatment with Tetanus Toxin and Cobalt Chloride. BioMed research international.

[10] McNamara, J. O. , (1994). Cellular and molecular basis of epilepsy. The Journal of Neuroscience. 14(6): 3413-3425.
[11] Shorvon, S. D., (2005). Handbook oF Epilepsy Treatment Forms, Causes and Therapy in Children and Adults 2nd edition. Massachusetts, USA: Blackwell Publishingl.

[12] Guo, Y., Baum, L. W., Sham, P. C., Wong, V., Ng, P. W., Lui, C. H. T., Sin, N. C., Tsoi, T. H., Tang, C. S., Kwan, J. S. et al. , (2012) Two-stage genome-wide association study identifies variants in CAMSAP1L1 as susceptibility loci for epilepsy in Chinese. Human molecular genetics. 21(5): 1184-1189.

[13] Ahmad, T., Shah, R., Zakaria, F. and Yun, L. L., (2000). Development Of Detection Model For Neuromagnetic Field. Proceedings of BIOMED. Kuala Lumpur: Universiti Malaysia. 119121.

[14] Yun, L. L., (2001). Homeomorfisma Antara Melalui Struktur Permukaan Riemann serta Deduksi Teknik Pembuktiannya bagi Homeomorfisma pemetaan Topologi Topografi kabur (FTTM). M.sc. thesis. University Teknologi Malaysia.

[15] Zakaria, F., (2002). Algorithma Penyelesaian Masalah Songsang Arus Tunggal Tak Terbatas MEG. M.sc. thesis. University Technology Malaysia.

[16] Yun, L. L., (2006). Algebraic Structures of Fuzzy Topographic Topological Mapping for Solving Neuromagnetic Inverse Problem. PhD. thesis. University Teknologi Malaysia.

[17] Ahmad, T., Shah, R., Yun, L. L., Zakaria, F. and Zarina, W. E., (2005). Homeomorphism of Fuzzy Topographic Topological Mapping (FTTM). Matematika. 1(21): 35- 42.

[18] Ahmad, T., Jamian, S. S. and Talib, J., (2010). Generalized Finite Sequence of Fuzzy Topographic Topological Mapping. Journal of Mathematics and Statistics. 6(2): 151- 156

[19] Sayed, M., and Ahmad,T,. (2013). Graph of Finite Sequence of fuzzy Topographic topological Mapping. Journal of Mathematics and Statistics. 9(1): 18-23.

[20] Sayed, M. and Ahmad, T., (2013). On Properties of the Graph of Fuzzy Topographic Topological Mapping. Malaysian Journal of Fundamental and Applied and Applied Sciences. 9(3):139-142. 